\title{
Viziune și principii de dezvoltare a politicii forestiere din România 2020-2030
}

\author{
L. Nichiforel, A. Baban, L. Bouriaud, V. Blujdea, I. Courig, M. Drăgoi, R. Melu, D. Nicolaescu, B. Popa, R.-E. Scrib- \\ an, S. Sfîrlogea, E. Stanciu, G. Stanciu, A. Orban, R. Vlad
}

Nichiforel L., Baban A., Bouriaud L., Blujdea V., Covrig I., Drăgoi M., Melu R., Nicolaescu D., Popa B., Scriban R.-E., Sfîrlogea S., Stanciu E., Stanciu G., Orban A., Vlad R. 2019. Vision and principles for the development of Romania's forest policy 2020-2030. Bucov. For. 19(2): 173-181

Abstract. Romania's forest policy is based on a long tradition in establishing and implementing the principles of sustainable management of forestry resources, based on a sound scientific and technical foundation. This resulted in a rigorous forestry regime, designed to operate efficiently under the conditions of state ownership over all forests. Over the past 30 years, Romania has gone through a period of transition towards a market economy with major institutional changes that took place in the forest sector through the restitution of forests and the privatisation of the administration, logging and forest industry sector. In this context, the regulatory system did not have the expected efficiency, which is reflected in a clear social tension, involving all stakeholders interested in and affected by the management of forests: private owners, public and private forest administration, logging and wood processing companies, environmental protection organisations, civil society, etc. The paper presents the process of elaborating a vision for sustainable forest management that would underlie a new public forest policy, in accordance with the international strategic documents and with the current challenges faced by the Romanian forest sector. The dialogue platform used in the elaboration of the vision has been coordinated by a university, precisely to ensure a unitary methodological approach to involve relevant experts and stakeholders in the process. The development of the vision used a stepwise participatory process based on the activity of a core group of experts followed by an extension of the group of experts, a public consultation process and a public debate. The result of the process is materialised in a set of eight sustainable forest management principles and four good governance principles. The implementation of the principles requires the identification, through an efficient and constructive communication between all stakeholders, of specific directions of action that have to be integrated in a new regulatory system that needs to be clear, easily monitored and effective in terms of practical results. Keywords sustainable forest management, forest policy, policy instruments, participatory approach

Authors. Liviu Nichiforel (nichiforel@usv.ro), Laura Bouriaud, Marian Drăgoi, Ramona-Elena Scriban - Ștefan cel Mare University of Suceava, Faculty of Forestry, 13 Universității, 720229 Suceava, Romania, Adrian Baban - Business Forest, Viorel Blujdea, Bogdan Popa - Universitatea Transilvania Braşov, Ilie Covrig - USAMV ClujNapoca, Radu Melu, Radu Vlad - WWF Romania, Daniel Nicolaescu - Ocolul Silvic Săliște, Sorin Sfîrlogea - Leanergy Consulting SRL, Erika Stanciu - Propark, Gabriel Stanciu - Ocolul Silvic Comunal Romuli RA, Alexandru Orban - NEPCon.

Manuscript received December 23, 2019; revised December 27, 2019; accepted December 30, 2019; online first December 31, 2019. 


\section{Introducere}

Gestionarea pădurilor prezintă un interes deosebit la nivel global, european și național, ținând cont de multitudinea de servicii ecosistemice pe care acestea le oferă. Pădurile joacă un rol determinant în îndeplinirea unor obiective globale conform Agendei 2030 pentru dezvoltare durabilă, adoptată de Organizația Națiunilor Unite (ONU, 2015). Pădurile au un rol crucial atât în atenuarea schimbărilor climatice și a efectelor acestora, cât și în asigurarea unor modele de consum și de producție durabile.

Politica forestieră din România se bazează pe o lungă tradiţie în stabilirea şi implementarea principiilor gestionării durabile a resurselor forestiere, aspect dovedit în special prin sistemul de zonare funcțională, care a precedat cu mult abordările actuale de gestionare durabilă a pădurilor din alte țări europene (Popa și Pache, 2016). Acest lucru s-a concretizat într-un regim silvic riguros, cu o temeinică fundamentare științifică și tehnică, creat să funcționeze eficient în condițiile proprietății etatice asupra sectorului naţional.

În ultimii 30 de ani, România a trecut printr-o perioadă de tranziţie către economia de piață cu schimbări instituţionale majore care au avut loc în sectorul forestier, prin retrocedarea pădurilor și privatizarea sectorului de exploatare-industrializare a lemnului și a serviciilor de administrare a pădurilor (Abrudan et al, 2009). La nivelul reglementărilor, s-a menţinut un sistem legislativ rigid, bazat aproape în totalitate pe instrumente de comandă și control (Nichiforel et al, 2018). În contextul acestor schimbări instituţionale majore sistemul de reglementare nu a mai avut eficiența scontată.

Neadaptarea politicii forestiere la contextul socio-politic actual, la noile provocări socio-economice și la noile strategii de conservare a biodiversității are ca efect o evidentă tensiune socială (Palaghianu și Nichiforel, 2016), implicând toate grupurile interesate și afectate de gestionarea pădurilor: proprietari 174 privați, administrație silvică de stat și privată, firme de exploatare și industrializare, organizații de protecția mediului, mediul academic și societatea civilă etc.

Experiența ultimilor ani în materie de dezbateri publice a arătat că, pe lângă o criză de imagine a sectorului forestier național, se constată o profundă criză de comunicare intra- și intersectorială, care a condus în repetate rânduri fie la blocaje decizionale, fie la supra-reglementare și sub-finanțare, fie la amânarea sine die a adoptării unor documente programatice (de exemplu, strategia forestieră națională) sau a creării unor structuri specifice intra- sau intersectoriale.

Lipsa unei viziuni naționale și unitare de gestionare durabilă a pădurilor, care să fie implementată într-un cadru strategic asumat și realist, reprezintă aşadar principalul risc sistemic pentru sectorul forestier. Această lipsă de viziune este reflectată într-o incoerență a politicii forestiere, chiar inevitabilă în condițile în care, începând cu 2007, mandatele secretarilor de stat răspunzători de domeniul pădurilor rareori au depăşit un an (Drăgoi și Toza, 2019).

\section{Scopul formulării unei viziuni de gestionare a pădurilor}

Numărul tot mai mare de iniţiative politice specifice sau conexe domeniului forestier, asumate la nivel internațional, european și național creează un mediu politic complex și fragmentat care trebuie să integreze obiective diverse și deseori conflictuale reieșite, de exemplu, din strategia de conservare a biodiversității, strategia de bio-economie sau din cea de dezvoltare rurală (Tabelul 1).

Este necesară, astfel, crearea unei viziuni de politică forestieră care să asigure un demers de bună guvernanță bazat pe coerența legislației din domeniul forestier, asumarea răspunderii și transparență și care să permită sinergii active cu alte sectoare care influențează sau sunt afectate de gestionarea pădurilor. 
Reafirmarea principiilor pentru gestionare durabilă a pădurilor Românei, într-un nou context vizionar, este importantă deoarece:

- schimbările sociale, economice și politice semnificative din ultimii 30 de ani au influ- ențat modul în care societatea privește "problematica" pădurilor și a silviculturii atât la nivel național, cât și la nivel european;

- potențialul multifuncțional al pădurilor din România trebuie gestionat într-un mod durabil

Tahelul1 Documente strategice de referință în elaborarea politicilor publice pentru sectorul forestier Strategic documents with relevance for the elaboration of the public forest policies

\begin{tabular}{|c|c|c|}
\hline Tipul de informație & Nivel european & Nivel național \\
\hline $\begin{array}{l}\text { Documente } \\
\text { programatice: } \\
\text { strategii, convenții, } \\
\text { directive, poziții } \\
\text { publice }\end{array}$ & 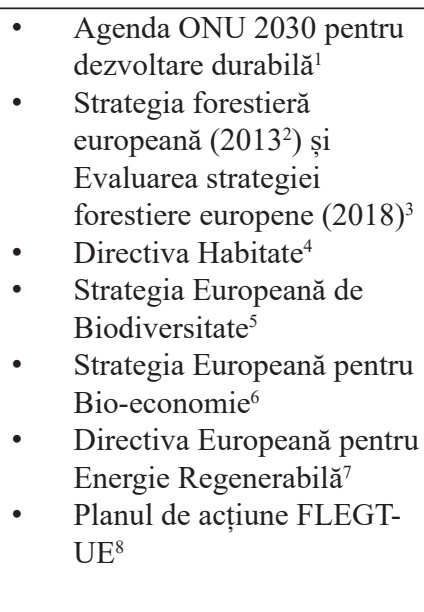 & 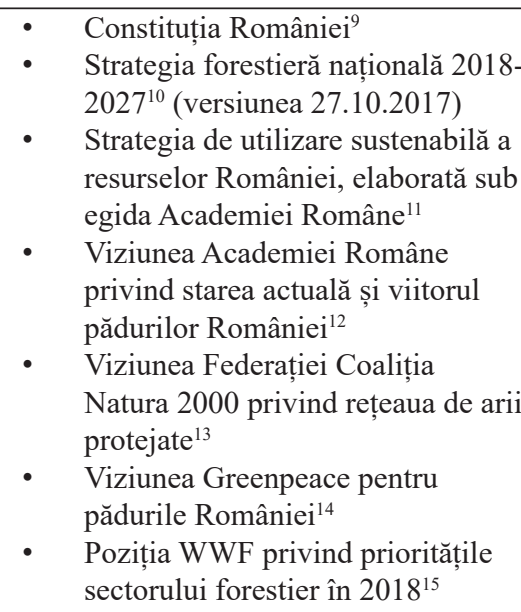 \\
\hline Informații statistice & $\begin{array}{ll}\text { - } & \text { Situația pădurilor europene } \\
2015^{16}(\mathrm{FAO} / \mathrm{FOREST} \\
\text { EUROPE) }\end{array}$ & $\begin{array}{ll} & \text { Rezultatele inventarului forestier } \\
& \text { național }(2018)^{17} \\
\text { - } & \text { Raport MAP privind starea } \\
\text { pădurilor }(2017)^{18}\end{array}$ \\
\hline
\end{tabular}

${ }^{1}$ https://www.globalgoals.org/

${ }^{2}$ https://eur-lex.europa.eu/resource.html?uri=cellar:2c1c71af-8384-11e3-9b7d-01aa75ed71a1.0003.01/DOC_1\&format=PDF

${ }^{3} \mathrm{https}$ //ec.europa.eu/info/sites/info/files/food-farming-fisheries/forestry/documents/report-progress-eu-forest-strategy-com-2018811-f1_en.pdf

${ }^{4} \mathrm{http} / / / \mathrm{ec}$.europa.eu/environment/nature/legislation/habitatsdirective/index_en.htm

${ }^{5} \mathrm{http}: / /$ ec.europa.eu/environment/nature/biodiversity/strategy/index_en.htm

${ }^{6} \mathrm{https}: / /$ ec.europa.eu/research/bioeconomy/index.cfm?pg=policy\&lib=strategy

${ }^{7}$ http://eur-lex.europa.eu/legal-content/EN/ALL/?uri=celex\%3A32009L0028

${ }^{8} \mathrm{http}: / /$ ec.europa.eu/environment/forests/illegal_logging.htm

${ }^{9} \mathrm{http}: / /$ www.cdep.ro/pls/dic/site.page?id=339

${ }^{10} \mathrm{http}: / /$ www.mmediu.ro/articol/strategia-forestiera-nationala-2018-2027/2409

${ }^{11} \mathrm{https} / /$ www.edu.ro/sites/default/files/Strategia-nationala-pentru-dezvoltarea-durabila-a-Rom\%C3\%A2niei-2030.pdf

${ }^{12} \mathrm{https}: / /$ academiaromana.ro/acadDeclaratii/d0509-AR-StareaPadurilor.pdf

${ }^{13} \mathrm{https} / / /$ regasesteromania.ro/wp-content/uploads/2018/10/viziunea-federatiei-coalitia-natura-2000.pdf

${ }^{14} \mathrm{https}$ //www.greenpeace.org/romania/ro/campanii/paduri/publicatii/viziune-Greenpeace-pentru-padurile-romaniei/

${ }^{15} \mathrm{http}: / /$ www.wwf.ro/resurse/comunicate_de_presa/?uNewsID=323271

${ }^{16} \mathrm{https}: / /$ foresteurope.org/state-europes-forests-2015-report/

${ }^{17} \mathrm{http} / / /$ roifn.ro/site/rezultate-ifn-2/

${ }^{18} \mathrm{http}$ ://apepaduri.gov.ro/wp-content/uploads/2014/07/Starea-p\%C4\%83durilor-\%C3\%AEn-anul-2017.pdf 
și echilibrat, astfel încât să se permită asigurarea corectă a tuturor serviciilor ecosistemice vitale furnizate de păduri, dar și distribuirea echitabilă a costurilor asociate furnizării acestora;

- este necesară creșterea rezilienței ecosistemelor forestiere la amenințările biotice și abiotice agravate de schimbările climatice și, de asemenea, trebuie promovat rolul esențial al pădurilor în atenuarea schimbărilor climatice; - sunt necesare instrumente de adresare a oportunităților și provocărilor rezultate din diversificarea tot mai mare a cererii de materie primă furnizată de păduri, atât pentru produse tradiționale, cât și pentru produsele noi, impulsionate de strategia de bio-economie.

În acest context, scopul prezentului demers științific a fost acela de sintetizare a unei viziuni de gestionare durabilă a pădurilor, care să se constituie într-o propunere pentru o nouă politică forestieră, în concordanță cu documentele strategice internaționale și cu provocările actuale din sectorul forestier național și din societatea românească.

Viziunea și principiile formulate pot constitui baza pentru identificarea, printr-o comuni- care eficientă și constructivă între toate părțile interesate, a direcțiilor specifice de acțiune pentru o abordare legislativă nouă care să se constituie într-un sistem de reglementare clar, ușor de monitorizat și eficient sub raportul rezultatelor practice.

\section{Ahordarea metodologică}

Elaborarea prezentei viziuni s-a creat în afara cadrului guvernamental, sub coordonarea unei universități, urmărind o abordare metodologică unitară și continuă de implicare a experților și grupurilor interesate în exprimarea opiniilor privind principiile de dezvoltare a unei noi politici forestiere.

Formularea cadrului principial al politicii forestiere se bazează pe următoarele etape:

- Stabilirea documentelor de referință în elaborarea politicilor publice ce interferează cu domeniul forestier (Tabelul 1) și identificarea principiilor și priorităților care reies din documentele strategice internaționale și naționale.

- Dezvoltarea unui cadru principial de elaborare a politicii publice forestiere, într-o abor-

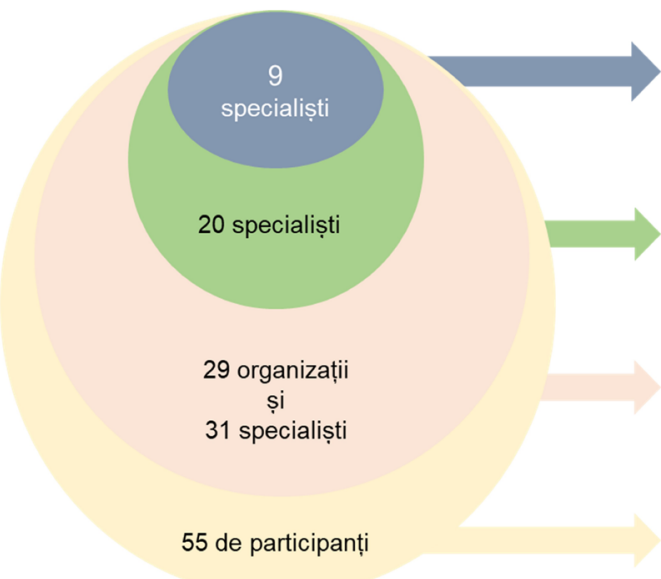

Grup de lucru:

4 întâlniri: Noiembrie - Martie 2019

Crearea unei versiuni preliminare: Vo

Grup consultativ:

4 întâlniri: Aprilie - August 2019

Formularea de opinii pe versiunea preliminară

Agrearea unei versiuni supusă consultării publice: V1

Consultare publică:

17.07-17.08.2019

Asumare instituțională sau personală a opiniilor

Dezbatere publică

Brașov, 4 septembrie 2019

Versiunea care integrează comentariile din

consultarea publică: V2

Figura 1 Implicarea grupurilor interesate în elaborarea documentului de viziune Stakeholders' involvement for the elaboration of the vision 
dare bazată pe activitatea unui grup de lucru specializat.

- Crearea unui forum de discuție al cadrului principial, forum deschis tuturor grupurilor interesate care au dorit să își exprime opiniile fie la întâlnirile organizate, fie prin comunicare scrisă (Figura 1).

În faza iniţială, (Noiembrie 2018 - Martie 2019), s-a constituit un grup de lucru din 9 persoane cu experiență în domeniul formulării politicilor forestiere. Aceștia au creionat, pe parcursul a patru întâlniri de lucru, un prim set de principii și obiective strategice ca punct de pornire a unui document programatic.

În cea de a doua fază (Aprilie-August 2019) grupul de experți a fost extins la un număr de 20 de persoane care au contribuit activ la îmbunătățirea documentului programatic și la atingerea unui consens privind principiile și obiectivele strategice. Grupul de lucru specializat a elaborat o versiune a documentului care a fost supusă consultării publice, în perioada 17 Iulie - 17 August 2019. În procesul de consultare publică s-au înregistrat 7 opinii asumate în numele unor organizații și 16 opinii asumate de specialiști.

Opiniile exprimate au fost analizate și incluse în versiunea documentului supusă dezbaterii publice organizate în data de 4 Septembrie 2019 la Brașov. La acest eveniment au luat parte 55 de participanţi din diferite organizații, incluzând administraţia forestieră de stat și privată, proprietari de pădure, garda forestieră, reprezentanți ai sectorului de exploatare și prelucrare a lemnului, organizații de protecția mediului și universități. Versiunea finală a luat în considerare și argumentele exprimate de participanți în cadrul dezbaterii publice și a fost făcută publică în data de 15 Octombrie 2019.

\section{Pădurea României: patrimoniu natural, mediu, re- Sursă}

Gestionarea durabilă a pădurilor presupune urmărirea unor teluri definite conform rezoluției Helsinki a Conferinței Ministeriale pri- vind protecția pădurilor din Europa (MCPFE, 1993). Ca urmare, politica forestieră națională trebuie să urmărească "administrarea și folosirea pădurilor şi terenurilor împădurite intr-un mod și la un nivel la care se menține biodiversitatea, productivitatea, capacitatea de regenerare, vitalitatea, potențialul de a $\hat{\imath} n-$ deplini acum și în viitor funcțiile ecologice, economice și sociale relevante, la nivel local, național și global fără a aduce prejudicii altor ecosisteme".

Viziunea formulată propune ca pădurile României să fie gestionate prin instrumente de politică forestieră adecvate și adaptate scopului propus care să răspundă în mod specific și echitabil nevoilor societăţii de:

- conservare a valorilor de patrimoniu natural;

- furnizare cu continuitate a serviciilor de mediu vitale;

- adaptare a practicilor de management la contextul schimbărilor climatice;

- asigurare a unui mediu economic stabil.

În acest fel, gestionarea pădurilor va aduce beneficii sporite societății, proprietarilor de pădure, comunităților locale și economiei naționale.

Transpunerea practică a acestei viziuni s-a concretizat în dezvoltarea unui set de opt principii de management forestier și patru principii de bună guvernanță, ca răspuns la țelurile necesar a fi urmărite pentru gestionarea durabilă a pădurilor. Aceste principii sunt prezentate sintetic mai jos, cu sublinierea principalelor obiective strategice.

\section{Principii de management forestier}

\section{P1. Fundamentarea și evaluarea riguroasă a politicilor forestiere.}

Planificarea politicilor forestiere trebuie să reducă riscul formulării unor reglementări direcționate de crize și de intenții politice de moment.

- Direcțiile strategice de politică forestieră 
trebuie să se bazeze pe analiza unor indicatori riguroşi de monitorizare a situaţiei pădurilor României și a impactului de mediu și socio-economic al activităților de management forestier.

- Transparentizarea procesului de evaluare şi a rezultatelor monitorizării acestor indicatori este esențială pentru a transmite către societate mesaje credibile și fundamentate metodologic privind starea pădurilor României. Identificarea celor mai eficiente instrumente politice de gestionare a pădurilor necesită argumente și date solide, ca răspuns la percepțiile bazate pe informații de slabă calitate.

\section{P2. Prevalența obligației de rezultat în aplicarea măsurilor de gestionare a pădurilor.}

Măsurile tehnice de gestionare a pădurilor trebuie să fie direcționate predominant către obținerea unor rezultate concrete și cât mai puțin către respectarea unor pași procedurali normativi care încurajează rutina şi deprofesionalizarea.

- Autoritatea trebuie să reglementeze obligații de rezultat exprimate prin indicatori relevanți și măsurabili (ca de exemplu, indicatori de structură optimă a arboretelor, adoptarea măsurilor de protecție instituite, respectarea unor termene şi perioade clare de intervenție, încadrarea în posibilitate, etc.), prin care se realizează totodată evaluarea performanțelor managementului forestier.

- Obligațiile de rezultat sunt diferențiate în raport cu obiectivele de gestionare a pădurilor, respectiv scara, intensitatea și riscurile aferente operațiunilor de management forestier.

- Responsabilitatea managementului forestier este aceea de a găsi metodele și instrumentele cele mai potrivite cu situația concretă pentru a obține rezultatele impuse. Acest lucru presupune flexibilitate în adoptarea celor mai bune practici și stimularea inovării și cercetării aplicate.

\section{P3. Menținerea integrității și stimularea crește- rii suprafeței pădurilor.}

Statul garantează menținerea integrității suprafețelor de pădure și sprijină creșterea suprafeței acoperite cu păduri și arbori, cu prioritate în zonele deficitare.

- Statul creează măsuri de sprijin financiar pentru integrarea în circuitul silvic a terenurilor cu potențial de utilizare forestieră (acoperite cu vegetaţie forestieră sau improprii pentru agricultură), cu scopul de a reduce presiunea asupra pădurilor naturale, de a îmbunătăți condițiile de mediu și de a crește capacitatea de stocare a carbonului.

- Țelurile de gospodărire pentru suprafețele împădurite în afara fondului forestier sunt stabilite de proprietari, în limita respectării unor criterii tehnice de bază.

\section{P4. Reprezentativitate, conectivitate ecologică și funcționalitate în conservarea biodiversității.}

Conservarea biodiversității este abordată prioritar prin:

- consolidarea rețelei naționale de arii naturale protejate;

- prin crearea unei rețele naționale de ecosisteme forestiere reprezentative;

- prin fundamentarea tehnică a unor măsuri specifice de conservare a biodiversității la nivel de arboret.

- Consolidarea managementului eficient al rețelei de arii naturale protejate din România presupune atât reevaluarea fundamentată științific a obiectivelor și măsurilor de conservare, cât și integrarea acestora cu instrumentele de planificare a măsurilor de management forestier.

- Este necesară fundamentarea și aplicarea de măsuri specifice pentru conservarea resurselor genetice forestiere, a elementelor de biodiversitate la nivel de arboret (menținerea „,arborilor pentru biodiversitate”, a „lemnului mort", a speciilor de interes comunitar, etc.) și de menținere și gestionare a habitatelor marginale. 


\section{P5. Continuitatea serviciilor ecosistemice vitale și justa compensare a serviciilor specifice.}

Gestionarea pădurilor presupune implementarea unor măsuri tehnice care să asigure furnizarea cu continuitate a serviciilor ecosistemice vitale, în regim normativ, obligatoriu indiferent de forma de proprietate și de suprafaţa aflată în proprietate.

- În raport cu zonarea funcțională, sunt stabilite măsurile tehnice necesare pentru oferirea unor servicii ecosistemice specifice, adiționale.

- Furnizarea serviciilor adiționale către societate este garantată în aceeași măsură ca respectarea drepturilor proprietarilor de a valorifica serviciile ecosistemice adiționale. Acest lucru presupune implementarea unor mecanisme de finanțare pentru serviciile adiţionale, sistem menit să responsabilizeze proprietarii și să maximizeze potențialul de furnizare a acestor servicii.

\section{P6. Adaptarea sistemului forestier la riscurile induse de schimbările climatice și la realiza- rea unei economii neutre din punct de vedere climatic.}

Adaptarea pădurilor la schimbări climatice se realizează prin măsuri active de gestionare, acolo unde pădurile nu sunt incluse în zone strict protejate.

- Este necesară o flexibilitate mai mare a deciziilor tehnice în raport de situațiile locale și de riscurile identificate.

- Rolul specific al sectorului forestier atât în captarea carbonului, cât și în stocarea acestuia în produse de lungă utilizare (case de lemn, mobilier etc.) este promovat prin instrumente economice și informaționale. Planurile de acțiune vor urmări cu prioritate: valorificarea și prelucrarea superioară a lemnului în produse cu lungă durată de viață; colectarea selectivă a deșeurilor de lemn și a mobilei scoase din uz; condiționarea achizițiilor publice de dobândirea unor certificate de proveniența sustenabilă a lemnului.
- Autoritatea implementează un instrument de monitorizare și un mecanism financiar, în vederea administrării cantităţilor de gaze cu efect de seră emise/sechestrate potrivit angajamentelor europene și internaționale de reducere a emisiilor asociate cu exploatarea terenurilor, schimbarea destinației terenurilor și silvicultură.

- Statul acordă cu prioritate sprijin financiar pentru măsuri silvice care nu aduc beneficii economice directe proprietarilor, dar sunt vitale pentru creșterea stabilității arboretelor și a gradului de stocare a carbonului (de exemplu, refacerea și îngrijirea arboretelor degradate afectate de perturbări naturale sau antropice sau lucrări de îngrijire şi conducere pre-comerciale).

\section{P7. Eficiența administrativă.}

Statul reduce la minimum costurile, precum și piedicile administrative şi birocratice, pentru activitățile pe care vrea să le promoveze a fi efectuate de proprietari şi administratori.

- Sarcinile administrative impuse de stat trebuie să fie fundamentate printr-o evaluare a costurilor ce derivă din acestea și o evaluare a eficienței implementării lor.

- Eficientizarea actului de administrare presupune implementarea unor instrumente digitale de suport şi de reducere a birocrației. Dezvoltarea platformei digitale trebuie să se facă în direcția creării unui Registru Unic de Evidență a Pădurilor, interconectat între instituțiile de administrare, avizare și control. Platforma trebuie să suplinească eficient avizările și raportările multiple şi să emită alerte cu rol de prevenție și informare.

Sistemul de evaluare, autorizare și punere în circulație a lemnului trebuie să asigure declararea transparentă şi monitorizarea tuturor intrărilor de lemn în piață, inclusiv în scopul fiscalizării acestora. Indiferent de forma de valorificare (lemn pe picior sau lemn fasonat), este necesar ca:

- evaluarea şi declararea volumului care intră în piaţă, precum şi urmărirea legalității și trasa- 
bilității lemnului să se realizeze la, și de la, momentul avizării transportului în punctul declarat de intrare în piață, printr-o recepție comună asumată de administrator și agentul economic. - sistemul de control al volumelor exploatate trebuie să se concentreze pe prima plasare pe piață a produselor de lemn și pe mecanisme de prevenție a recoltării și transportării ilegale a lemnului.

Este necesară, de asemenea, o strategie specifică, susținută de un cadru legal care să promoveze accesibilizarea pădurilor, prin investițiile publice și private în construirea de drumuri forestiere și prin posibilitatea de concesionare a drumurilor existente de către proprietarii/administratorii deserviți de aceste drumuri.

\section{P8. Asigurarea funcțiilor de recreere a pădurilor și a obiectivelor de dezvoltare a comunităților locale.}

Populaţia beneficiază liber de serviciile recreative și sanogene oferite de pădure, cu stabilirea unor reguli de acces și vizitare a pădurilor în spiritul respectului față de mediul natural și față de proprietarul terenului. Accesul la resursele forestiere care se valorifică în scop comercial se face doar cu acordul proprietarului pădurii.

Dezvoltarea socio-economică a comunităților locale este susținută prin implicarea lor adecvată în planuri strategice locale și prin stimularea valorificării și procesării superioare a lemnului și a produselor forestiere nelemnoase, în sensul creșterii valorii adăugate pe plan local.

\section{Principii de bună guvernanță}

\section{PI. Coerența legislativă și asumarea răspunde- rii.}

Coerența legislativă trebuie asigurată printr-un nou cadru simplificat și eficient de reglementare a gestionării pădurilor şi de asumare a răspunderii. Politica forestieră trebuie să ur- mărească ca statul să își exercite, în mod transparent și eficient, rolurile de reglementare, de monitorizare și control, de suport instituțional şi de proprietar de pădure.

- Este necesară delimitarea clară a sarcinilor și responsabilităților persoanelor și organizațiilor din sectorul forestier, pe baza unui set de criterii etice și tehnice de evaluare a firmelor cheie din domeniu și reprofesionalizarea actului de administrare a pădurilor.

- Monitorizarea și controlul managementului forestier trebuie să utilizeze o abordare bazată pe riscuri și criterii obiective și transparente de control, precum și o raportare clară a eficienței corpului de control.

- Suportul instituțional presupune asigurarea cu prioritate a accesului la toate măsurile de sprijin financiar disponibile la nivel european pentru sectorul forestier.

- Statul, ca proprietar de păduri, aplică un model de gestionare responsabilă și eficientă a pădurilor avute în proprietate.

- Statul, ca proprietar de păduri, trebuie să își asume rolul de mediator a competiției în piața lemnului, prin menținerea valorii de vânzare a masei lemnoase la un preț sustenabil pentru populație și industrie.

\section{PII. Respectarea proprietății și responsabilizare activă.}

Stabilirea și implementarea instrumentelor de politică forestieră trebuie să considere respectarea drepturilor de proprietate.

- Gestionarea proprietăților private, în special a celor de mici dimensiuni, necesită măsuri specifice care să susțină viabilitatea economică a gestionării pădurilor, în scopul co-interesării proprietarilor pentru păstrarea pădurilor în proprietate și pentru gestionarea lor responsabilă.

- Proprietarul are exercițiu deplin asupra drepturilor și obligațiilor aferente proprietății forestiere, ceea ce-i atrage angajarea răspunderii proprii. 


\section{PIII. Abordarea strategică a managementului forestier și integrarea sectorială.}

Statul urmărește la nivel instituțional integrarea politicilor forestiere cu politicile sectoriale adiacente asumate prin tratate, acorduri internaționale, directive și strategii europene, precum și transpunerea acestora la nivel naţional (de exemplu, integrarea cu politicile energetice, agricole, cu cele de infrastructură, cu cele de turism, dezvoltare rurală etc.).

- Statul dezvoltă, în cadrul unui proces participativ, soluții integrate de reducere a presiunii asupra pădurii, de folosire superioară a resurselor forestiere, de impunere a unor criterii de sustenabilitate în folosirea biomasei forestiere în scop energetic și de valorificare economică a serviciilor ecosistemice.

- Programele de educație forestieră informează populația privind rolul pădurii și caracterul regenerabil al resursei forestiere şi promovează folosirea lemnului provenit din păduri gestionate durabil.

\section{PIV. Transparența și participarea factorilor interesați.}

Statul asigură implementarea unui sistem transparent pentru accesul publicului la informații actuale, cu posibilitatea utilizării platformei informaționale pentru generarea de diferite rapoarte tematice de interes public.

- Autoritatea publică asigură implicarea tuturor factorilor interesați în procesul decizional, de control pasiv și de monitorizare a performanței exercitării gestionării durabile a pădurilor, cu scopul de a descuraja potențialele conflicte de interes și pentru a crește capacitatea instituțională, suplinind legislația orientată prioritar, pe instrumente de comandă și control.

\section{O invitație la un dialog structurat și constructiv}

Documentul de viziune propus ${ }^{19}$ se adresează tuturor celor implicați în activităţi de management forestier, fiind expresia unui consens larg al factorilor interesați, bazat pe obiectivitate și expertiză. Documentul se constituie într-o invitație la un dialog structurat, adresată atât factorilor politici cu rol decizional în formularea politicilor publice cât și organizațiilor reprezentative din sectorul forestier.

Asumarea unui punct de vedere comun privind cadrul strategic de dezvoltare a politicii forestiere este o necesitate pentru sprijinirea autorităţii publice în a găsi și implementa soluții viabile la probleme concrete și pentru a limita perpetuarea, prin supra-reglementări, a eșecurilor decizionale anterioare.

\section{Bibliografie}

Abrudan, I.V., Ioras, F., Marinescu, V., Ioenscu, O., Horodnic, S.A., Sestras, R., 2009. Developments in the Romanian forestry and its linkages with other sectors. Notulae Botanicae Horti Agrobotanici Cluj-Napoca, 37(2), pp.14-21.

Drăgoi, M., Toza, V. (2019). Did forestland restitution facilitate institutional amnesia? Some evidence from Romanian forest policy. Land, 8(6), 99. https://doi. org/10.3390/land8060099

MCPFE (Ministerial Conference on the Protection of Forests in Europe) 1993. Resolution H1. General Guidelines for the Sustainable Management of Forests in Europe https://www.foresteurope.org/docs/MC/MC_he1sinki_resolutionH1.pdf

Nichiforel, L., Keary, K., Deuffic, P., Weiss, G., Thorsen, B.J., Winkel, G., Avdibegović, M., Dobšinská, Z., Feliciano, D., Gatto, P. ...\& Bouriaud, L., 2018. How private are Europe's private forests? A comparative property rights analysis. Land Use Policy, 76, pp.535-552.

ONU (Organizatia Naţiunilor Unite). 2015. Agenda 2030 pentru dezvoltare durabilă. Disponibil la https://www. globalgoals.org/

Palaghianu, C., Nichiforel, L., 2016. Între percepții și precepte în dialogul despre pădurile României. Bucovina Forestieră, 16(1), pp.3-8.

Popa, B., Pache, R.G., 2016. The concept of ecosystem services-the solution to support the regulation efforts of the forestry sector in Romania. Revista Pădurilor, 131(3/4), pp.41-53.

${ }^{19}$ Versiunea integrala a documentului este disponibilă la http:// silvic.usv.ro/dpfr/viziune politica forestiera.pdf 